\title{
Articles
}

\section{Combinatorial Study of the Optimization of $\mathrm{Y}_{2} \mathrm{O}_{3}: \mathrm{Bi}, \mathrm{Eu} \operatorname{Red}$ Phosphors}

\author{
Ting-Shan Chan, ${ }^{\dagger}$ Chia-Chen Kang, ${ }^{\dagger}$ Ru-Shi Liu, ${ }^{*}, \dagger$ Lei Chen,,$\stackrel{\dagger}{\dagger}$ Xiao-Nan Liu,${ }^{\ddagger}$ \\ Jian-Jun Ding, ${ }^{\ddagger}$ Jun Bao, ${ }^{\ddagger}$ and Chen Gao \\ Department of Chemistry, National Taiwan University, Taipei 106, Taiwan, and National Synchrotron \\ Radiation Laboratory and Structure Research Laboratory, University of Science \& Technology of China, \\ Hefei 230026, China
}

Received January 8, 2007

\begin{abstract}
The present investigation aims at the synthesis of $\left(\mathrm{Y}_{2-x} \mathrm{Eu}_{x} \mathrm{Bi}_{y}\right) \mathrm{O}_{3}$ red phosphor materials using the combinatorial chemistry method. We developed square-type arrays consisting of 90 compositions to obtain the optimum composition of co-dopants in a $\mathrm{Y}_{2} \mathrm{O}_{3}$ host. The optimized composition was found to be $\left(\mathrm{Y}_{2-x} \mathrm{Eu}_{x} \mathrm{Bi}_{y}\right) \mathrm{O}_{3}(x=0.16-0.18, y=0.08-0.10)$. The screening of the compositions was investigated by analysis of the emission spectrum under $365 \mathrm{~nm}$ UV excitation arising from the energy transfer between $\mathrm{Bi}^{3+}$ and $\mathrm{Eu}^{3+}$ ions. The results of the photoluminescence excited by ultraviolet agree well with the conventional-scale synthesis results, indicating that the combinatorial screening method is fast, reliable, reproducible, and applicable to the study of powder materials with relatively quick calcinations at high synthesis temperatures.
\end{abstract}

\section{Introduction}

White light-emitting diodes (LEDs) have attracted interest because of their most challenging application as a replacement for conventional incandescent bulbs and fluorescent lamps. ${ }^{1}$ It is generally accepted that white-light generation is likely to be achieved in one of two ways. First, blue, green, and red diodes can be combined to yield white light, and second, in a very cheap way, a single white LED can be obtained from the combination of an LED chip with phosphors. A device has been successfully developed, using the latter approach, by using YAG:Ce as a broadband yellow phosphor coated on a blue LED chip. However, this phosphor faces serious problems of thermal quenching, poor color rendition, and a narrow visible range. As an alternative, a novel approach has been suggested which uses a vacuum or near-UV excitation instead of a blue LED in combination with red, green, and blue phosphors to generate white LEDs. ${ }^{2}$ Among the various red phosphors, $\mathrm{Eu}^{2+}$-doped $\mathrm{Y}_{2} \mathrm{O}_{3}$ is considered to be the most promising candidate, compared with other sulfides, ${ }^{3-10}$ because of its chemical stability. Red phosphors $\left(\mathrm{Y}_{1.84-y} \mathrm{Eu}_{0.16} \mathrm{Bi}_{y} \mathrm{O}_{3}\right)(0<y \leq 0.12)$ were synthesized by homogeneous coprecipitation and solid-state reactions in one of our previous investigations. ${ }^{11} \mathrm{We}$ found that the efficiency of the phosphor can be enhanced by energy transfer from $\mathrm{Bi}^{3+}$ to $\mathrm{Eu}^{3+}$. These red phosphors could be

\footnotetext{
* To whom correspondence should be addressed. E-mail: rsliu@ntu.edu.tw

$\dagger$ Department of Chemistry.

$\doteqdot$ National Synchrotron Radiation Laboratory and Structural Research Laboratory.
}

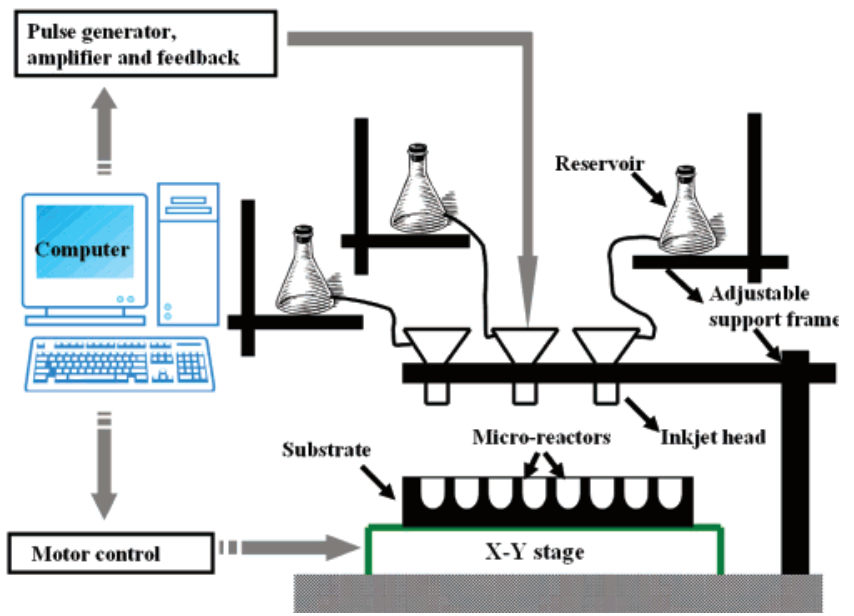

Figure 1. Schematic diagram of the drop-on-demand inkjet delivery system

excited by $350-400 \mathrm{~nm}$ UV light and used in white LEDs. It was observed that when the concentration of $\mathrm{Bi}^{3+}$ ions increased gradually, the lattice constant and color purity were increased because of the increased energy-transfer rate.

Recently, combinatorial chemistry has been widely applied to the synthesis of a variety of materials, such as drugs in pharmaceutical analysis or various inorganic functional materials. ${ }^{12-14}$ The use of a combinatorial approach will make it possible to search a fairly large phase space rapidly and exhaustively. The present investigation aims at the application of the liquid-state combinatorial chemistry method to the synthesis of phosphor materials. Combinatorial methods 


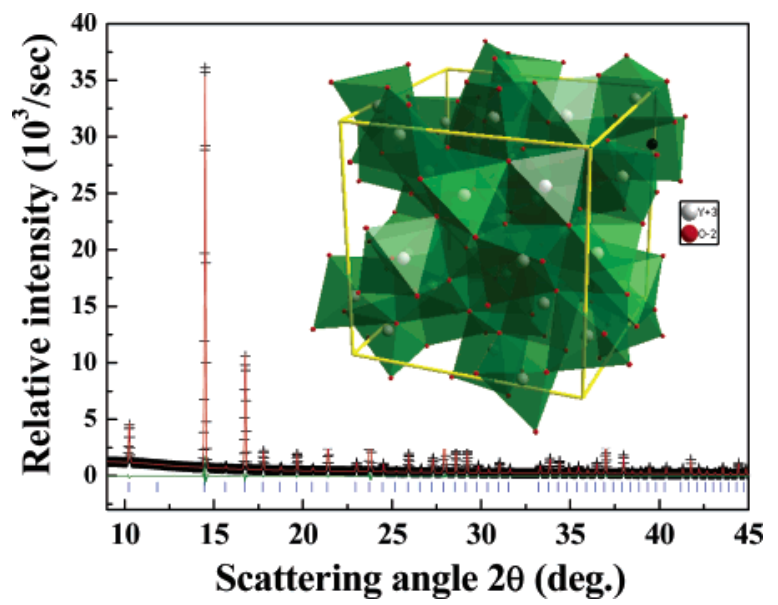

Figure 2. Observed (crosses), calculated (solid line), and differences (bottom) synchrotron XRD pattern of $\left(\mathrm{Y}_{2-x} \mathrm{Eu}_{x} \mathrm{Bi}_{y}\right) \mathrm{O}_{3}(x=$ $0.16, y=0.16$ ) at $300 \mathrm{~K}$ with $\lambda=0.7749 \AA$. Bragg reflections are indicated by tick marks. An ideal crystal structure is also shown in the inset.

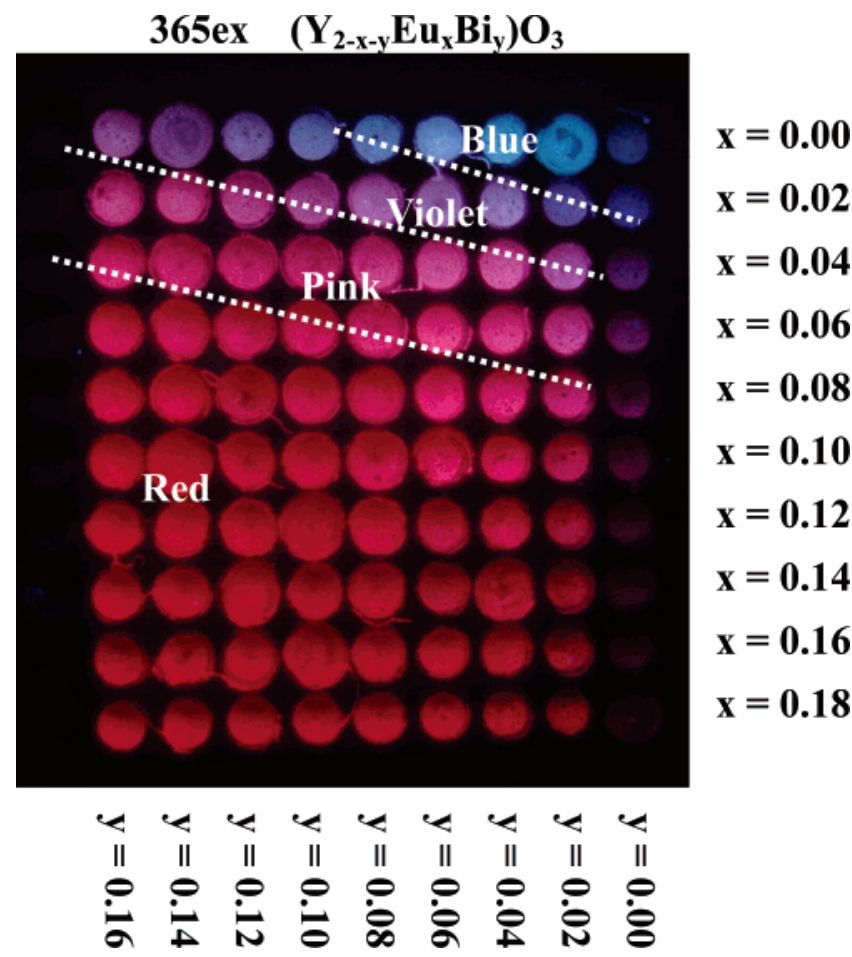

Figure 3. Composition map and photoluminescence photography of the library excited under $365 \mathrm{~nm}$ UV light for $\left(\mathrm{Y}_{2-x} \mathrm{Eu}_{x} \mathrm{Bi}_{y}\right) \mathrm{O}_{3}$.

make it possible to rapidly synthesize, process, and analyze large libraries (with hundreds to thousands of members), dramatically accelerating the rate at which these experiments can be designed, executed, and analyzed. Thus, the aim of this article is to further investigate our previously reported work ${ }^{11}$ on the optimization of $\mathrm{Y}_{2} \mathrm{O}_{3}: \mathrm{Bi}$, Eu red phosphors using the combinatorial chemistry method. To the best of our knowledge, this is the first report to use a combinatorial chemistry method to study $\mathrm{Eu}^{3+}$ and $\mathrm{Bi}^{3+}$ ions co-doped efficiently in a $\mathrm{Y}_{2} \mathrm{O}_{3}$ host.

\section{Experimental Section}

The schematic diagram of the drop-on-demand inkjet delivery system developed is shown in Figure 1. The eight

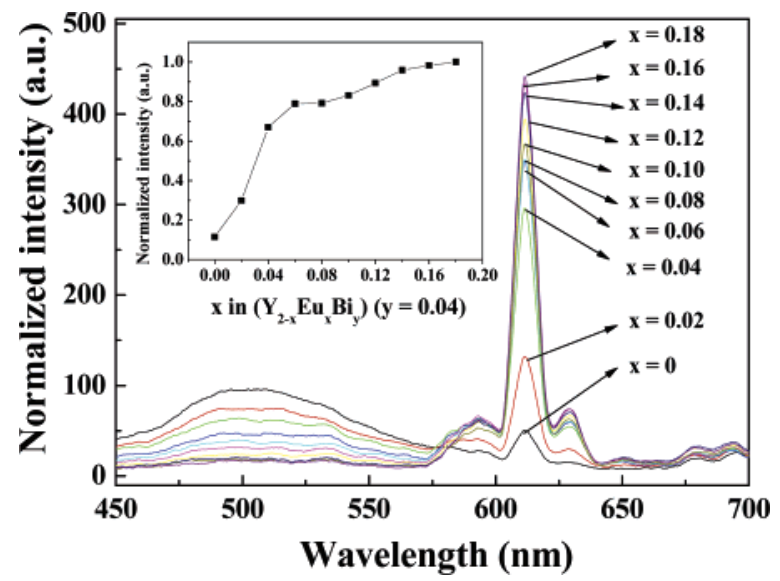

Figure 4. Emission spectrum of $\left(\mathrm{Y}_{2-x} \mathrm{Eu}_{x} \mathrm{Bi}_{y}\right) \mathrm{O}_{3}(y=0.04)$ with different $\mathrm{Eu}^{3+}$ contents. The normalized intensity as a function of $x$ is also shown in the inset.

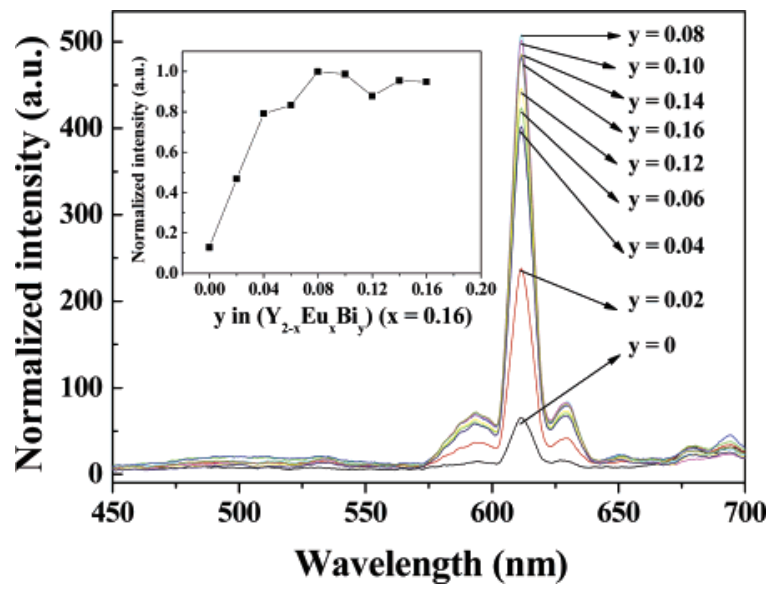

Figure 5. Emission spectrum of $\left(\mathrm{Y}_{2-x} \mathrm{Eu}_{x} \mathrm{Bi}_{y}\right) \mathrm{O}_{3}(x=0.16)$ with different $\mathrm{Eu}^{3+}$ contents. The normalized intensity as a function of $y$ is also shown in the inset.

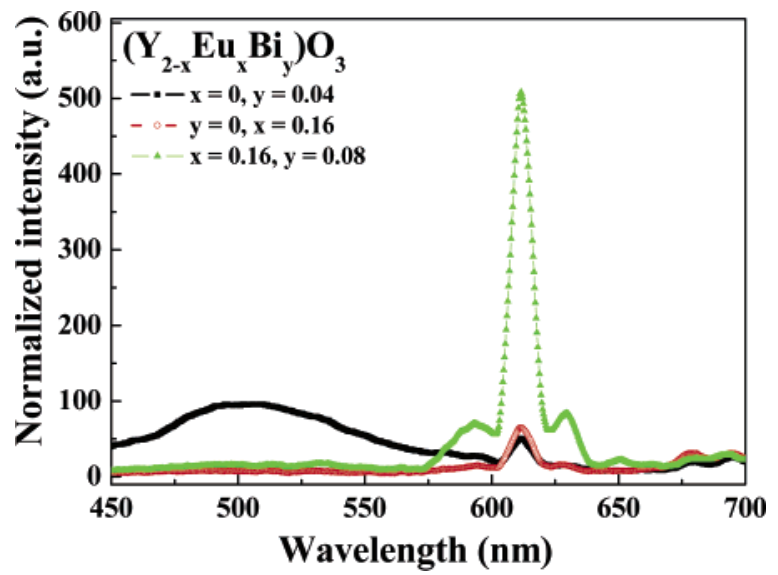

Figure 6. Emission spectrum of $\left(\mathrm{Y}_{2-x} \mathrm{Eu}_{x} \mathrm{Bi}_{y}\right) \mathrm{O}_{3}(x=0, y=0.04)$, $\left(\mathrm{Y}_{2-x} \mathrm{Eu}_{x} \mathrm{Bi}_{y}\right) \mathrm{O}_{3}(x=0.16, y=0)$, and $\left(\mathrm{Y}_{2-x} \mathrm{Eu}_{x} \mathrm{Bi}_{y}\right) \mathrm{O}_{3}(x=0.16$, $y=0.08)$ phosphors measured under $365 \mathrm{~nm}$ UV excitation.

independent piezoelectric inkjet heads and the $\mathrm{X}-\mathrm{Y}$ stage are controlled by the computer via the driving circuit and motor controller. Each inkjet head is connected to a suspension reservoir through a tube, and the substrate with a microreactor array is fixed on the stage. Moreover, the emission spectra of the samples in the library were measured using an automatic system. The main parts of the system 
Table 1. Crystallographic Data for $\left(\mathrm{Y}_{2-x} \mathrm{Eu}_{x} \mathrm{Bi}_{y}\right) \mathrm{O}_{3}(x=0.16, y=0.16)$ Phosphor, Constraints on Atomic Position, and $U_{\text {iso }}{ }^{a}$

\begin{tabular}{|c|c|c|c|c|c|}
\hline atoms & $x$ & $y$ & $z$ & occupancy & $U_{\text {iso }}\left(\AA^{2}\right)$ \\
\hline $\mathrm{Y}(1)$ & 0.25 & 0.25 & 0.25 & 0.84 & $2.89(6)$ \\
\hline $\mathrm{Eu}(1)$ & 0.25 & 0.25 & 0.25 & 0.08 & $2.89(6)$ \\
\hline $\mathrm{Bi}(1)$ & 0.25 & 0.25 & 0.25 & 0.08 & $2.89(6)$ \\
\hline$Y(2)$ & $-0.0309(6)$ & 0 & 0.25 & 0.84 & $2.67(3)$ \\
\hline $\operatorname{Eu}(2)$ & $-0.0309(6)$ & 0 & 0.25 & 0.08 & $2.67(3)$ \\
\hline $\operatorname{Bi}(2)$ & $-0.0309(6)$ & 0 & 0.25 & 0.08 & $2.67(3)$ \\
\hline \multirow[t]{2}{*}{$\mathrm{O}$} & $0.3917(4)$ & $0.1510(5)$ & $0.3807(4)$ & $2.80(2)$ & $2.80(2)$ \\
\hline & & & reliability factors & \multicolumn{2}{|c|}{ interatomic distances $(\AA)$} \\
\hline space group & $\operatorname{Ia} \overline{3}$ (Cubic) & $\chi^{2}$ & $0.68 \%$ & $\mathrm{M}(1)-\mathrm{M}(1)(\times 3)$ & $3.5506(4)$ \\
\hline \multirow[t]{2}{*}{ cell params } & $a=b=c=10.6822(9) \AA$ & $R_{\mathrm{p}}$ & $1.82 \%$ & $\mathrm{M}(1)-\mathrm{M}(1)(\times 3)$ & $4.0174(5)$ \\
\hline & $\alpha=\beta=\gamma=90^{\circ}$ & $R_{\mathrm{wp}}$ & $3.11 \%$ & $\mathrm{M}(1)-\mathrm{M}(2)(\times 2)$ & $3.5493(4)$ \\
\hline \multirow[t]{5}{*}{ cell vol } & $1218.93(2) \AA^{3}$ & & & $\mathrm{M}(1)-\mathrm{M}(2)(\times 2)$ & $4.0310(4)$ \\
\hline & & & & $\mathrm{M}(1)-\mathrm{O}(\times 2)$ & $2.2877(2)$ \\
\hline & & & & $\mathrm{M}(1)-\mathrm{O}(\times 2)$ & $2.3150(2)$ \\
\hline & & & & $\mathrm{M}(1)-\mathrm{O}(\times 2)$ & $2.3566(2)$ \\
\hline & & & & $\mathrm{M}(2)-\mathrm{O}(\times 2)$ & $2.2884(2)$ \\
\hline
\end{tabular}

${ }^{a} \mathrm{Y}=\mathrm{Eu}=\mathrm{Bi} ; \mathrm{M}=\mathrm{Y}, \mathrm{Eu}$, and $\mathrm{Bi}$.

consist of an $\mathrm{Hg}$ Lamp, a portable optical fiber spectrometer (Ocean Optics, Inc., model SD2000), and an X-Y stage. More details can be found in a previous report. ${ }^{15}$ With the aid of a homemade inkjet delivery system, precursors (>99.99\% purity) such as $0.1 \mathrm{M} \mathrm{Y}\left(\mathrm{NO}_{3}\right)_{3} \cdot 6\left(\mathrm{H}_{2} \mathrm{O}\right), 0.01 \mathrm{M}$ $\mathrm{Eu}_{2} \mathrm{O}_{3}$, and $0.01 \mathrm{M} \mathrm{Bi}\left(\mathrm{NO}_{3}\right)_{3} \cdot 5\left(\mathrm{H}_{2} \mathrm{O}\right)$ were dissolved in nitric acid and deionized water. Then the correct amount of each solution was collected in an $\mathrm{Al}_{2} \mathrm{O}_{3}$ ceramic substrate according to the composition map with the assistance of a computer programmed inject system. The substrates containing the solutions were first dried at $100{ }^{\circ} \mathrm{C}$ for $1 \mathrm{~h}$ in an oven and then placed in an electric furnace where the temperature was slowly increased to $500{ }^{\circ} \mathrm{C}$ at the rate of $3{ }^{\circ} \mathrm{C} \mathrm{min}-1$. Finally, the dried samples were pulverized and successively sintered at $1300{ }^{\circ} \mathrm{C}$ for $3 \mathrm{~h}$ in an ambient atmosphere.

Some of the chosen samples among those in the library were taken out of the $\mathrm{Al}_{2} \mathrm{O}_{3}$ ceramic substrate and then examined by synchrotron X-ray diffraction (XRD) analysis with a large Debye-Scherrer camera installed at the BL01C2 beam line at the National Synchrotron Radiation Research Center (NSRRC) in Taiwan. The synchrotron XRD data were collected in a $2 \theta$ range from 0.16 to $45^{\circ}$ with a step interval of $0.01^{\circ}$ and $\lambda=0.7749 \AA$. The GSAS program ${ }^{16}$ was used for the Rietveld refinements to obtain information on the crystal structures of $\left(\mathrm{Y}_{2-x} \mathrm{Eu}_{x} \mathrm{Bi}_{y}\right) \mathrm{O}_{3}$.

\section{Results and Discussion}

Figure 2 shows a typical example of matrix samples of the experimental, calculated, and difference synchrotron XRD patterns of $\left(\mathrm{Y}_{2-x} \mathrm{Eu}_{x} \mathrm{Bi}_{y}\right) \mathrm{O}_{3}(x=0.16, y=0.16)$ at $300 \mathrm{~K}$ with $\lambda=0.7749 \AA$. An ideal crystal structure is also shown in the inset. The observed peaks can be indexed on the basis of a cubic unit cell (space group $I a \overline{3}$ ). However, we could not obtain the occupancy refinements for complex cation substitution because of the difficulty in using the X-ray powder diffraction data resulting from instrumental limits. Here, we assume that the $\mathrm{Eu}^{3+}$ and $\mathrm{Bi}^{3+}$ ions substituted into the $\mathrm{Y}^{3+}$ sites follow an ideal distribution. We therefore kept the values of occupancies constant for the (Y, Eu, Bi) sites in our data refinements. The final structural parameters and selected bond lengths are given in Table 1. The atomic position of $\mathrm{M}(1)(\mathrm{M}=\mathrm{Y}, \mathrm{Eu}$, and $\mathrm{Bi})$ corresponds to the 24d site with $C_{2}$ symmetry which does not have inversion symmetry, and the atomic position of $\mathrm{M}(2)(\mathrm{M}=\mathrm{Y}, \mathrm{Eu}$, and $\mathrm{Bi}$ ) is the $8 \mathrm{~b}$ site with $S_{6}$ symmetry which has inversion symmetry. As seen from Table 1 , the final $R$ factors of the refinement are $R_{\mathrm{p}}=1.82 \%, R_{\mathrm{wp}}=3.11 \%$, and $\chi=0.86$ and the lattice constants are $a=b=c=10.6822$ (9) $\AA$.

The composition map and luminescent photograph of the $\left(\mathrm{Y}_{2-x} \mathrm{Eu}_{x} \mathrm{Bi}_{y}\right) \mathrm{O}_{3}$ library under $365 \mathrm{~nm}$ UV excitation are shown in Figure 3. The square-type arrays consist of 90 compositions with co-doped different $\mathrm{Eu}^{3+}$ contents from $x=0$ to 0.18 and $\mathrm{Bi}^{3+}$ contents from $y=0$ to 0.16 . The lamp light was illuminated evenly over the library to obtain a relative comparison. It is apparent that the color change is from blue $\rightarrow$ violet $\rightarrow$ pink $\rightarrow$ red with increasing Eu content.

Figure 4 presents the emission spectra of $\left(\mathrm{Y}_{2-x} \mathrm{Eu}_{x} \mathrm{Bi}_{y}\right) \mathrm{O}_{3}$ $(y=0.04)$, which varies with the $\mathrm{Eu}^{3+}$ content in the library. The normalized intensity from $\lambda=601-622 \mathrm{~nm}$ according to Figure 4 is also shown in the inset. When phosphors were excited under $365 \mathrm{~nm}$, because of the energy transfer from $\mathrm{Bi}^{3+}$ to $\mathrm{Eu}^{3+}, \mathrm{Bi}^{3+}$ acted as a sensitizer for $\mathrm{Eu}^{3+}$ emission, and these emission spectra consist of lines in the red region of the spectra corresponding to the transition from the excited ${ }^{5} \mathrm{D}_{0}$ to ${ }^{7} \mathrm{D}_{J}(J=0,1,2,3,4)$ of the $\mathrm{Eu}^{3+}$ ion. ${ }^{17}$ The most intense line at $612 \mathrm{~nm}$ corresponds to the hypersensitive transition between the ${ }^{5} \mathrm{D}_{0}$ to ${ }^{7} \mathrm{D}_{2}$ level of the $\mathrm{Eu}^{3+}$ ion. In addition, as can be seen in Figure 4, the intensity increased with increasing $\mathrm{Eu}^{3+}$ content, and the maximu intensity observed is for $x=0.16-0.18$, which is in good agreement with results using the traditional solid-state reaction method from one of our previous studies. ${ }^{11}$ The result indicates that an appropriate amount of $\mathrm{Eu}^{3+}$ was properly doped into the $\mathrm{Y}_{2} \mathrm{O}_{3}$ matrix and formed homogeneous material in the library.

Figure 5 presents the emission spectra of $\left(\mathrm{Y}_{2-x} \mathrm{Eu}_{x} \mathrm{Bi}_{y}\right) \mathrm{O}_{3}$ $(x=0.16)$, which varies with the $\mathrm{Bi}^{3+}$ content in the library. The normalized intensity from $\lambda=601-622 \mathrm{~nm}$ according to Figure 5 is also shown in the inset. The concentration 
quenching effect is clearly exhibited as evident from Figure 5 , and the $\mathrm{Bi}^{3+}$ concentration of maximum intensity is found in $y=0.08-0.10$, which is similar to the findings in one of our previous reports $\left(\mathrm{Bi}^{3+}=0.06\right) .{ }^{11}$ Therefore, the optimum composition was found to be $\left(\mathrm{Y}_{2-x} \mathrm{Eu}_{x} \mathrm{Bi}_{y}\right) \mathrm{O}_{3}(x=0.16-$ $0.18, y=0.08-0.10)$ using the combinatorial chemistry method.

Figure 6 shows the emission spectra of $\left(\mathrm{Y}_{2-x} \mathrm{Eu}_{x} \mathrm{Bi}_{y}\right) \mathrm{O}_{3}(x$ $=0, y=0.04),\left(\mathrm{Y}_{2-x} \mathrm{Eu}_{x} \mathrm{Bi}_{y}\right) \mathrm{O}_{3}(x=0.16, y=0)$, and $\left(\mathrm{Y}_{2-x} \mathrm{Eu}_{x} \mathrm{Bi}_{y}\right) \mathrm{O}_{3}(x=0.16, y=0.08)$. It is well-known that the efficiency of the phosphor can be greatly enhanced by the energy transfer from the ${ }^{1} \mathrm{~S}_{\mathrm{o}} \rightarrow{ }^{3} \mathrm{P}_{1}$ transition of the $\mathrm{Bi}^{3+}$ ion to the $\mathrm{Eu}^{3+}$ ion. ${ }^{18-19}$ Here, we can get a good understanding of the energy transfer by comparing the three emission spectra. For $\left(\mathrm{Y}_{2-x} \mathrm{Eu}_{x} \mathrm{Bi}_{y}\right) \mathrm{O}_{3}(x=0, y=0.04)$, the broad peak located at about 450-550 nm was observed clearly and is caused by the blue-green light radiated by the $\mathrm{Bi}^{3+}$ ion. Thus, in the $\left(\mathrm{Y}_{2-x} \mathrm{Eu}_{x} \mathrm{Bi}_{y}\right) \mathrm{O}_{3}(x=0.16, y=0)$ sample, we did not find this phenomenon. Moreover, in the $\left(\mathrm{Y}_{2-x} \mathrm{Eu}_{x} \mathrm{Bi}_{y}\right) \mathrm{O}_{3}$ $(x=0.16, y=0.08)$ sample, with $\mathrm{Bi}^{3+}$ concentration increased to $y=0.08$, the most intense line at $612 \mathrm{~nm}$ was significantly increased. Such an observation could be key evidence for the effective energy transfer from $\mathrm{Bi}^{3+}$ to $\mathrm{Eu}^{3+}$.

\section{Conclusion}

Red phosphors $\left(\mathrm{Y}_{2-\mathrm{x}} \mathrm{Eu}_{x} \mathrm{Bi}_{y}\right) \mathrm{O}_{3}(x=0-0.18, y=0-0.16)$ have been synthesized using the combinatorial chemistry method. The optimum composition was found to be $\left(\mathrm{Y}_{2-x} \mathrm{Eu}_{x} \mathrm{Bi}_{y}\right) \mathrm{O}_{3}(x=0.16-0.18, y=0.08-0.10)$. On the basis of the above results, it is reasonable to believe that the developed combinatorial chemistry method makes the search process for a new oxide-based red phosphor for use in white LEDs possible.

Acknowledgment. We thank the National Science Council of Taiwan (Grant 95-2113-M-002-009) and the Ministry of Economic Affairs of Taiwan (Grant 95-EC-17-A-078-S1043) for financial support.

\section{References and Notes}

(1) Nakamura, S.; Fasol, G. The Blue Laser Diode: GaN Based Light Emitters and Lasers; Springer: Heidelberg, Germany, 1997.

(2) Shimizu, Y.; Sakano, K.; Noguchi, Y.; Moriguchi, T. U.S. Patent 5,998,925, 1999.

(3) Ando, M.; Ono, Y. A. J. Appl. Phys. 1990, 68, 3578.

(4) Pham-Thi, M. J. Appl. Phys. 1992, 31, 2811.

(5) Yamashita, N. J. Electrochem. Soc. 1993, 140, 840.

(6) Pham-Thi. M.; Ruelle, N.; Tronc, E.; Simons, D.; Vivien, D. Jpn. J. Appl. Phys. 1994, 33, 1876.

(7) Luo, X.; Li, D. SID Digest 1992, 92, 175.

(8) Swiatek, K.; Karpinska, K.; Godlewski, M.; NiinistÖ, L.; Leskelä, M. J. Lumin. 1994 60-61, 923.

(9) Choi, H.; Kim, C. H.; Pyun, C. H.; Kim, S. J. J. Solid State Chem. 1998, 138, 149.

(10) Wu, J.; Newman, D.; Viney, I. V. F. J. Lumin. 2002, 99, 237.

(11) Chi, L. S.; Liu, R. S.; Lee, B. J. J. Electrochem. Soc. 2005, 152, J93.

(12) McFarland, E. W.; Weinberg, W. H. Trends Biotechnol. 1999, 17, 107.

(13) Senkan, S. M. Nature 1998, 394, 350.

(14) Xiang, X-D. Ann. Rev. Mater. Sci. 1999, 29, 149.

(15) Chen, L.; Bao, J.; Gao. C. J. Comb. Chem. 2004, 6, 699.

(16) Larson, A. C.; Von Dreele, R. B. Generalized Structure Analysis System (GSAS); Los Alamos National Laboratory Report LAUR 86-748; Los Alamos National Laboratory: Los Alamos, NM, 1994.

(17) Blasse, G.; Grabmaier, B. C.; Luminescent Materials; Springer: Berlin, 1994; p 117.

(18) Li, B.; Sun, S. J. Inorg. Mater. 1993, 8, 207.

(19) Datta, R. K. J. Electrochem. Soc. 1967, 114, 1137.

\section{CC070006L}

